\title{
Profile of intravenous glyburide for the prevention of cerebral edema following large hemispheric infarction: evidence to date
}

This article was published in the following Dove Press journal:

Drug Design, Development and Therapy

\author{
Zachary A King' \\ Kevin N Sheth' \\ W Taylor Kimberly ${ }^{2}$ \\ J Marc Simard ${ }^{3}$ \\ 'Department of Neurology, Division \\ of Neurocritical Care and Emergency \\ Neurology, Yale University School \\ of Medicine, New Haven, CT, USA; \\ ${ }^{2}$ Department of Neurology, Division \\ of Neurocritical Care and Emergency \\ Neurology, Massachusetts \\ General Hospital, Boston, MA, USA; \\ ${ }^{3}$ Department of Neurosurgery, \\ University of Maryland School of \\ Medicine, Baltimore, MD, USA
}

\begin{abstract}
Glyburide (also known as glibenclamide) is a second-generation sulfonylurea drug that inhibits sulfonylurea receptor 1 (Sur1) at nanomolar concentrations. Long used to target $\mathrm{K}_{\mathrm{ATP}}$ (Sur1-Kir6.2) channels for the treatment of diabetes mellitus type 2, glyburide was recently repurposed to target Sur1-transient receptor potential melastatin 4 (Trpm4) channels in acute central nervous system injury. Discovered nearly two decades ago, SUR1-TRPM4 has emerged as a critical target in stroke, specifically in large hemispheric infarction, which is characterized by edema formation and life-threatening brain swelling. Following ischemia, SUR1-TRPM4 channels are transcriptionally upregulated in all cells of the neurovascular unit, including neurons, astrocytes, microglia, oligodendrocytes and microvascular endothelial cells. Work by several independent laboratories has linked SUR1-TRPM4 to edema formation, with blockade by glyburide reducing brain swelling and death in preclinical models. Recent work showed that, following ischemia, SUR1-TRPM4 co-assembles with aquaporin-4 to mediate cellular swelling of astrocytes, which contributes to brain swelling. Additionally, recent work linked SUR1-TRPM4 to secretion of matrix metalloproteinase-9 (MMP-9) induced by recombinant tissue plasminogen activator in activated brain endothelial cells, with blockade of SUR1-TRPM4 by glyburide reducing MMP-9 and hemorrhagic transformation in preclinical models with recombinant tissue plasminogen activator. The recently completed GAMES (Glyburide Advantage in Malignant Edema and Stroke) clinical trials on patients with large hemispheric infarctions treated with intravenous glyburide (RP-1127) revealed promising findings with regard to brain swelling (midline shift), MMP-9, functional outcomes and mortality. Here, we review key elements of the basic science, preclinical experiments and clinical studies, both retrospective and prospective, on glyburide in focal cerebral ischemia and stroke.

Keywords: glyburide, sulfonylurea receptor 1, stroke, cerebral ischemia, brain swelling, malignant edema, matrix metalloproteinase- 9
\end{abstract}

\section{Introduction}

In 2013, stroke accounted for a staggering $11.8 \%$, around 6.5 million, deaths worldwide. ${ }^{1}$ In $10 \%-12 \%$ of cases, stroke is accompanied by rapid edema formation that causes brain swelling, leading to increased ischemic damage, brain herniation and death. ${ }^{2}$ Largely because of brain swelling, stroke patients who develop severe edema have a reported mortality of up to $60 \%-80 \%{ }^{2,3}$

At present, recombinant tissue plasminogen activator (rtPA), which gained the US Food and Drug Administration approval in 1996, is the only pharmaceutical agent approved for use in stroke. For a variety of reasons, the use of rtPA is limited, with only about $20 \%$ of stroke patients receiving this treatment. ${ }^{4-7}$
Correspondence: J Marc Simard

Department of Neurosurgery, University of Maryland School of Medicine,

22 S. Greene St, Suite SI2D, Baltimore,

MD $21201-1595$, USA

$\mathrm{Tel}+\mathrm{I} 4103280850$

$\mathrm{Fax}+14103280124$

Email msimard@som.umaryland.edu 
Although brain swelling may increase the morbidity and mortality of stroke patients, few efficacious therapies exist. Brain swelling in stroke patients is often treated with unproven drug interventions such as mannitol and hypertonic saline, or with the potentially life-saving but morbid surgical procedure, decompressive craniectomy. ${ }^{8}$ Novel treatments are urgently needed to prevent brain swelling rather than react to the already swollen brain.

The $A b c c 8$ gene encodes sulfonylurea receptor 1 (Sur1), which co-associates with two distinct ion channel

A
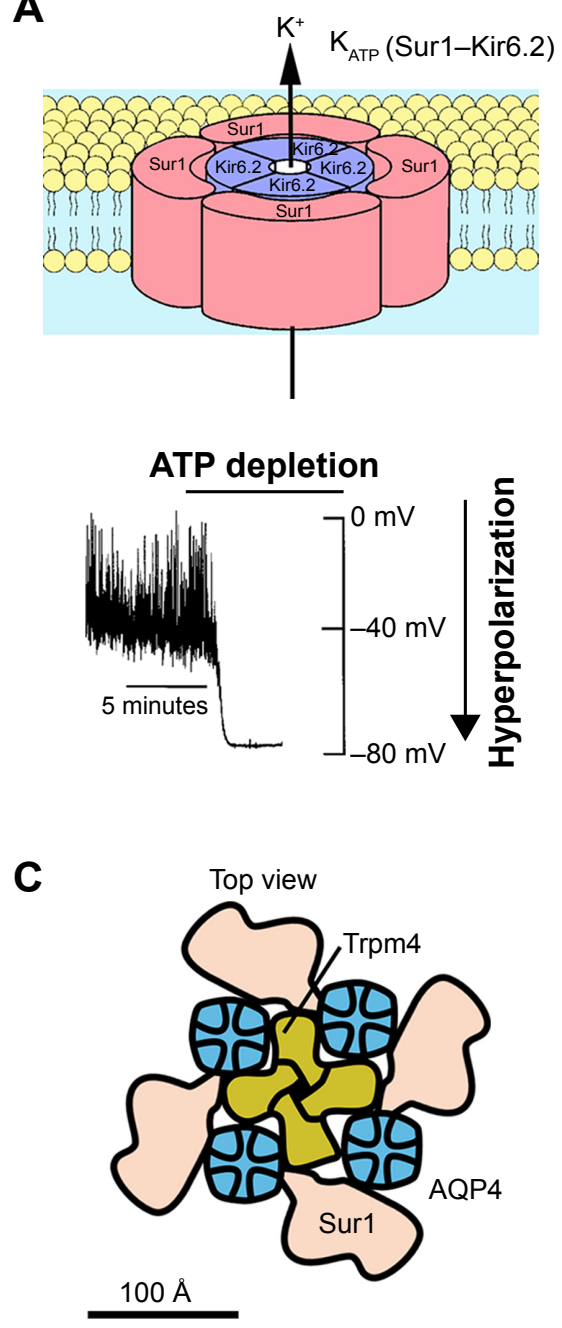

subunits, Kir6.2 and transient receptor potential melastatin 4 (Trpm4), to form unique ion channels. The Sur1-Kir6.2 association generates an adenosine triphosphate (ATP)-sensitive $\mathrm{K}^{+}\left(\mathrm{K}_{\text {ATP }}\right)$ channel found in pancreatic $\beta$ cells and neurons. ${ }^{9-11}$ The SUR1-TRPM4 association generates an ATP-sensitive non-selective cation channel that is not constitutively expressed, but is upregulated after central nervous system (CNS) injury. ${ }^{12}$ Sur1 serves as the essential regulator for both $\mathrm{K}_{\text {ATP }}$ (Sur1-Kir6.2) and SUR1-TRPM4 channels. However, the two channels have diametrically opposed functional

B
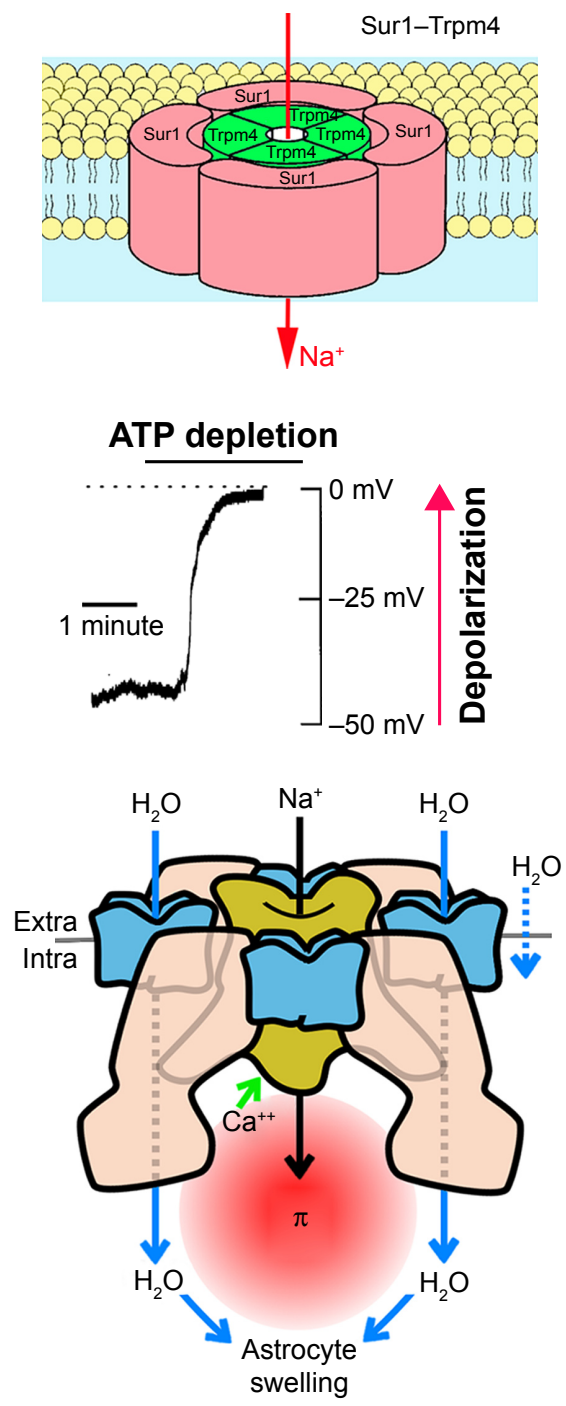

Figure I Depictions of the $\mathrm{K}_{\text {ATP }}$ (Sur I-Kir6.2) and the SURI-TRPM4 channels.

Notes: (A, B) The hetero-octameric structure comprising four Surl subunits and four Kir6.2 subunits depicted for $\mathrm{K}_{\text {ATP }}$ is known. The structure depicted for the SUR I-TRPM4 channel is hypothesized by analogy. Also shown are the principal physiological actions of the two channels when they are activated by ATP depletion: I) outward flux of $\mathrm{K}^{+}$via the $\mathrm{K}^{+}$-selective pore-forming subunit, Kir6.2, resulting in hyperpolarization with the $\mathrm{K}_{\mathrm{ATP}}$ channel and 2) inward flux of $\mathrm{Na}^{+}$via the nonselective monovalent cation pore-forming subunit, Trpm4, resulting in depolarization with the SURI-TRPM4 channel. Simard JM, Woo SK, Schwartzbauer GT, Gerzanich V. Sulfonylurea receptor I in central nervous system injury: a focused review. J Cereb Blood Flow Metab. 32(9):1699-1717. Copyright (? [2012] (SAGE Journals). Reprinted by permission of SAGE Publications. ${ }^{14}$ (C, left) Putative model of SUR I-TRPM4-AQP4 complex, showing AQP4 tetramers (blue) intercalated between SURI monomers (pink) and interacting with the central tetrameric TRPM4 (green); protein profiles and relative protein sizes are based upon previously published structures for AQP4, SURI and TRP channels; overall channel topology is based on the structure of the $\mathrm{K}_{\text {ATP }}$ channel. (C, right) Model of SUR I-TRPM4-AQP4 water flux showing that raised intracellular $\mathrm{Ca}^{2+}$ triggers SURI-TRPM4 channel activation and Na ${ }^{+}$influx, resulting in raised osmotic pressure $(\pi)$ which, in turn, drives water influx (blue arrows) through AQP4. Copyright @ 20I8. John Wiley and Sons. Adapted from Stokum JA, Kwon MS, Woo SK, et al. SUR I-TRPM4 and AQP4 form a heteromultimeric complex that amplifies ion/water osmotic coupling and drives astrocyte swelling. Glia. 20I8;66(I):I08-I25.48 Abbreviations: AQP4, aquaporin-4; SURI, sulfonylurea receptor I; TRPM4, transient receptor potential melastatin 4. 
effects. $\mathrm{K}_{\mathrm{ATP}}$ channel activation allows for the outward flow of $\mathrm{K}^{+}$, which hyperpolarizes the cell (Figure 1). ${ }^{13}$ SUR1TRPM4 channel activation allows for the inward flow of $\mathrm{Na}^{+}$, which depolarizes the cell (Figure 1). Persistent unopposed activation of SUR1-TRPM4 can lead to cytotoxic edema and necrotic cell death. ${ }^{14,15}$

Under ischemic conditions, almost all CNS cell types, including neurons, astrocytes, oligodendrocytes, microglia and microvascular endothelial cells, increase Sur1 expression. This holds true for both animal models ${ }^{16-18}$ and humans. ${ }^{19,20}$ Trpm4 is concurrently upregulated with Sur $1 .^{21}$

Glyburide targets Sur1 and inhibit Sur1-regulated channel activity. Historically, glyburide was used orally as a treatment for diabetes mellitus type 2 , targeting the $\mathrm{K}_{\text {ATP }}$ channel in pancreatic $\beta$ cells. ${ }^{11}$ Recent evidence has advanced the notion that glyburide may be crucial for treating edema in patients with stroke. To that end, an intravenous (IV) formulation of glyburide has been developed for the treatment of stroke. An IV formulation allows for a constant serum level of glyburide as opposed to the oral administration in which the serum level can vary depending on stomach $\mathrm{pH}$. IV glyburide also allows for closer dosage control in case of blood glucose changes, a key factor when administering glyburide to a non-diabetic population. For all these reasons, glyburide and its target SUR1-TRPM4 are important avenues for stroke treatment.

\section{Sur I expression under conditions of ischemia Animal models of stroke}

Under normal conditions within the CNS, only a fraction of neurons express Sur1, and Sur1 subunits form only $\mathrm{K}_{\mathrm{ATP}}$ channels. ${ }^{22-24}$ After brain injuries such as ischemia, however, CNS tissues upregulate SUR1-TRPM4 channels. ${ }^{12}$

Sur1 is transcriptionally upregulated over the first several hours after induction of ischemia. In a rat stroke model with permanent mechanical middle cerebral artery occlusion (MCAo), Abcc 8 mRNA, which encodes Sur1, is increased 2.5-fold at 3 hours and Sur1 protein is increased 2.5-fold at 8 hours. ${ }^{16}$ After 105 minutes of transient MCAo followed by 1 hour of reperfusion, only microvascular endothelial cells show increased Sur1 transcription, ${ }^{25}$ whereas after 3 hours of reperfusion, neurons also show upregulation of Sur $1 .^{25}$

Rat models of stroke subjected to 4.5 hours MCAo followed by a 30-minute tPA infusion showed dramatic 7- to 11-fold increases in Sur1 expression up to 24 hours after the occlusion. ${ }^{26}$ Increased expression of $A b c c 8$ mRNA has been confirmed by in situ hybridization under ischemic conditions, confirming the de novo synthesis of Sur1 in stroke conditions. ${ }^{16,17}$ Notably, while Sur1 is transcriptionally upregulated, neither the $\mathrm{K}_{\text {ATP }}$ channel protein, Kir6.2, which typically co-associates with Surl during normal CNS function, nor its corresponding mRNA is upregulated. ${ }^{16}$ However, both Trpm4 and its mRNA are highly upregulated in ischemic conditions, ${ }^{21,27}$ consistent with SUR1-TRPM4 channel expression.

Recent work has shown that Sur1 also is upregulated in a porcine MCAo model of stroke, ${ }^{28}$ a finding of importance given that the pig brain, like that of the human, is gyrencephalic, and not lissencephalic, like that of the rodent.

\section{Human stroke}

In a study of human autopsy specimens from stroke patients, Sur1 was found to be transcriptionally upregulated in neurons, astrocytes and vascular endothelial cells, ${ }^{19}$ which aligns with prior case reports. ${ }^{29}$ Samples acquired posthumously from 15 patients who expired within 31 days after focal infarcts were analyzed. Sur1 was significantly elevated in all specimens. Sur1 had differential upregulation patterns over time, depending on the CNS cell types examined. Astrocytes and microglia showed continuous increases in Sur1 expression. Neurons and endothelium showed the largest Sur1 elevations during the first week, after which the levels decreased but remained significantly different from controls. Upregulation of Sur1 was corroborated using in situ hybridization for $A b c c 8$ mRNA.

A second study from this group examined the levels of Trpm4 in the same autopsy specimens. ${ }^{20}$ Similar to Sur1, Trpm4 showed a differential upregulation profile depending on the cell type. In neurons, Trpm4 was upregulated significantly post-stroke, after which the levels decreased but remained significantly elevated out to 31 days. Endothelial cells and neutrophils showed persistent upregulation, which was unchanged over time. Astrocytes near the infarct showed progressively increasing activation.

The analysis also determined that Sur1 and Trpm4 co-associate in the post-stroke period, using Förster resonance energy transfer to demonstrate co-association. ${ }^{20}$ Additionally, neurons and endothelial cells, which were positive for Sur1 and Trpm4, showed signs of membrane irregularities consistent with damage from cytotoxic edema, which has been postulated to be caused by SUR1-TRPM4 channel opening in rodent stroke models. 


\section{Surl as a cell death mediator}

Persistent activation of the SUR1-TRPM4 channel plays a major role in necrotic cell death of a variety of CNS cell types. ${ }^{15,21,30}$ As mentioned, under ischemic conditions, the entire neurovascular unit, including neurons, astrocytes, microglia, oligodendrocytes and endothelial cells, expressed SUR1TRPM4 channels. Accidental cell death is caused by a different mechanism than programmed cell death. ${ }^{15}$ Programmed cell death follows a series of events aimed at inducing cell death. By contrast, accidental death occurs when normal cellular processes go awry, such as when ATP is severely depleted.

Most cell death in ischemic stroke can be ascribed to accidental cell death. SUR1-TRPM4 channel upregulation in ischemic conditions is not meant to induce cell death. The channel normally prevents increasing intracellular calcium, a tell-tale sign of neuronal injury. ${ }^{31,32}$ However, ischemia causes depletion of intracellular ATP, which, in turn, causes sustained activation of SUR1-TRPM4 channels. This prolonged opening allows an excess of sodium influx, which causes water to move into the cell, resulting in cell swelling and accidental cell death. ${ }^{15}$

\section{Targeting Surl in cerebral ischemia}

Glyburide targets Sur1 in both SUR1-TRPM4 and $\mathrm{K}_{\text {ATP }}$ channels. ${ }^{33}$ Blockade is caused by an increase in the likelihood that the channel remains in a closed state for a long time. Glyburide does not alter open channel dwell times or impede the movement of ions through the open channel. Glyburide's inhibitory effects on Sur1 channel opening can be negated by an antibody directed against a cytoplasmic loop of Sur $1 .{ }^{33}$ Glyburide's potency increases at low $\mathrm{pH}$ because glyburide, a weak acid, becomes more protonated at low $\mathrm{pH}$, increasing its lipid solubility and allowing it to more easily infiltrate the lipid membrane and bind to Sur $1 .{ }^{16,34}$ This mirrors prior observation on $\mathrm{K}_{\mathrm{ATP}}$ channels, which are similarly targeted by glyburide. ${ }^{35}$

Glyburide cannot penetrate the normal blood-brain barrier (BBB) ${ }^{36}$ This corroborates the observation that, although neurons express $\mathrm{K}_{\mathrm{ATP}}$ (Sur1-Kir6.2) channels, there are no reports of CNS side effects attributed to sulfonylureas, despite decades of clinical use in diabetic patients. ${ }^{14,22}$ However, glyburide's entry into the brain increases after brain injury, as the $\mathrm{pH}$ decreases due to lactic acidosis. ${ }^{37}$ In addition, BBB disruption after ischemia also aids glyburide's penetrance into damaged brain. Studies using the fluorescent BODIPY-glyburide (constant infusion, $75 \mathrm{ng} / \mathrm{h}$ ) ${ }^{16}$ as well as $\left[{ }^{3} \mathrm{H}\right]$ glyburide (single injection, $100 \mu \mathrm{Ci}$ intraperitoneal; specific activity not specified $)^{38}$ have shown that glyburide cannot be detected in a normal brain, but appears in significant quantities following brain injury. As such, low doses of glyburide can have salutary effects in brain injury with minimal impact on pancreatic insulin secretion. ${ }^{14}$

\section{Inhibiting Sur I after ischemia improves outcomes in rat models}

Microvascular dysfunction follows focal ischemic brain injury. ${ }^{39,40}$ This dysfunction manifests initially as ionic edema followed by vasogenic edema. Ionic edema derives its name from the ion-rich fluid that enters the interstitium when the tight junctions of the BBB continue to function properly during ischemia. When the tight junctions become disrupted, the edema fluid becomes essentially a plasma filtrate, which is termed vasogenic edema. Both of these processes cause an influx of mass into the brain, which causes brain swelling that can worsen the original injury. If severe, malignant cerebral edema can lead to death.

A component of this microvascular dysfunction involves the upregulation of Sur1. Glyburide has been used to target Sur1 in several preclinical animal models of stroke from multiple laboratories, all of which demonstrate that Sur1 inhibition by glyburide reduces edema and leads to better outcomes in the stroke models. The original work reporting on the salutary effects of glyburide in ischemia ${ }^{16,17,26,41,42}$ has been replicated by independent laboratories. ${ }^{43-45}$

Following CNS injury, including ischemia, the astrocytic water channel, aquaporin-4 (Aqp4), is recognized to play a crucial role in edema formation and edema resolution. ${ }^{46,47}$ Normally, Aqp4 is expressed in a highly polarized manner at the astrocytic endfoot, but following injury, Aqp4's polarized localization is lost, with expression occurring throughout the plasmalemma, a phenomenon termed Aqp4 dysregulation. Recent work showed that in a model of ischemia, Aqp4 dysregulation is accompanied by its co-assembly with SUR1-TRPM4, and that the heteromultimeric macromolecular complex, SUR1-TRPM4-AQP4, is responsible for astrocyte swelling (Figure 1). ${ }^{48}$ In ischemia, astrocyte swelling is believed to contribute importantly to brain swelling. Thus, the reduction in brain swelling observed with glyburide treatment may be due to reductions not only in ionic and vasogenic edema, but also in astrocyte swelling.

\section{Lethal rat models of stroke}

Glyburide's therapeutic efficacy has been tested in rat models of malignant infarction that mimic the high mortality rates $(60 \%-80 \%)$ seen in humans. A model using particle embolization showed significant malignant edema, as measured by increased brain tissue water at 8 hours, and had $65 \%$ mortality at 7 days. ${ }^{16}$ Glyburide infusion shortly after ischemia 
significantly reduced brain tissue water and reduced mortality to $24 \%$. An alternative model, 6-hour temporary MCAo, generated transient thrombosis of middle cerebral artery (MCA) branches with spontaneous return of blood flow 2-3 hours after removal of the occluder. ${ }^{17}$ Similar to the previous model, robust hemispheric swelling (21\%) and high mortality (67\% at 24 hours) were observed. Glyburide infusion at 6 hours, at the time of occluder withdrawal, decreased hemispheric swelling by two thirds and reduced mortality to $5 \%$. In this same model, glyburide and decompressive craniectomy, a common surgical intervention for excessive brain swelling, were compared. Administered at 6 hours, the two treatments had identical mortality reductions. However, glyburide was superior to decompressive craniectomy in neurological tests over the ensuing 2 weeks.

\section{The therapeutic time window in a rat model of stroke}

Because brain swelling after stroke requires several hours to develop, it was postulated that the therapeutic time window for glyburide might be longer than what is encountered in typical neuroprotection studies. Glyburide's efficacy was tested in another clinically relevant model of stroke - a 4.5-hour temporary MCAo plus rtPA $(0.9 \mathrm{mg} / \mathrm{kg} \mathrm{IV}$, as in humans) administered at the time occluder withdrawal, with the effects of drug administration as late as 10 hours being evaluated. ${ }^{26}$ In control animals, hemispheric volume increased substantially at both 10 hours $(8 \%)$ and 24 hours (15\%); $53 \%$ of controls died by 48 hours. Infusion of glyburide in conjunction with rtPA at 4.5 hours reduced swelling by half and mortality $>3$-fold. These improvements also manifested as better long-term neurological outcomes for glyburide-treated animals compared to controls. More compelling, when glyburide was administered 5.5 hours after tPA infusion, a full 10 hours after the onset of ischemia, nearly identical decreases in swelling reduction at 24 hours and mortality at 48 hours were observed compared to glyburide given with rtPA at 4.5 hours.

\section{Interaction between rtPA and glyburide}

Because rtPA is the only approved drug for use in stroke, it was important to assess a possible interaction between rtPA and glyburide. First, in vitro experiments were carried out, which showed that the drug did not inhibit clot lysis induced by rtPA, and so should not interfere with rtPA's beneficial thrombolytic effect in stroke. ${ }^{42}$ Second, in vitro experiments using Wistar and SHR rat models were carried out to determine whether glyburide would complement the effects of rtPA. These models utilized a 6-hour MCAo followed by high-dose rtPA treatment after occluder withdrawal. ${ }^{42}$ Hemispheric volume grew more steeply than in previously discussed models (26\%) and, as expected, high rates of hemorrhagic conversion were observed. Administration of glyburide at 6 hours, along with rtPA, reduced hemispheric swelling by more than half and markedly decreased hemorrhagic transformation. Glyburide treatment alone reduced mortality and improved neurological scores, but the best outcomes were observed in rats treated with both rtPA and glyburide, indicating a possible synergistic effect of the two treatments.

The observation that rtPA-associated hemorrhagic transformation was reduced by glyburide remained unexplained until recently. In new work, it was shown that, in activated brain endothelium, rtPA induces phasic secretion of matrix metalloproteinase-9 (MMP-9) and causes activation of SUR1-TRPM4 channels. ${ }^{49}$ Although tonic secretion of MMP-9 by activated endothelium was not affected, glyburide inhibited phasic secretion of MMP-9 induced by rtPA. Thus, glyburide acts as a partial, indirect inhibitor of MMP-9, which is expected to be beneficial in stroke, especially in patients treated with rtPA.

\section{Rat models of stroke with combinatorial glyburide and hypothermia}

Hypothermia has been one of the most studied potential treatments for ischemic stroke. ${ }^{50}$ A 2016 meta-analysis showed that preclinical evidence for hypothermia treatment after stroke has been consistently positive. ${ }^{50}$ However, the two largest clinical trials, Intravascular Cooling in the Treatment of Acute Stroke (ICTuS) 1 and 2, showed no positive effect on outcome for hypothermia treatment. ${ }^{51,52}$

These results may have been affected by the relatively short therapeutic time window for hypothermia. ${ }^{53}$ In preclinical experiments, hypothermia can be initiated immediately after arterial occlusion. However, for a variety of reasons, this is not usually possible in a clinical setting. ${ }^{54}$ Thus, it is possible that hypothermia has not been successfully translated to human trials because of a relatively short therapeutic time window.

$\mathrm{Wu}$ et al examined the possibility of using glyburide to extend the therapeutic time window for hypothermia in an MCAo rat model. ${ }^{45}$ The study replicated prior findings that hypothermia at 6 hours after vessel occlusion failed to decrease cerebral edema and infarct volume. However, 
when both glyburide and hypothermia were administered at 6 hours, infarct volume and hemispheric swelling were significantly reduced compared to hypothermia alone and glyburide alone (Figure 2). ${ }^{45}$ This difference persisted at 8 hours, but at 10 hours there was no difference between glyburide/hypothermia treatment and glyburide only treatment. However, glyburide still reduced hemispheric swelling when administered 10 hours post-vessel occlusion, consistent with prior work. ${ }^{26}$

Treatment with glyburide and hypothermia at 6 hours post-occlusion showed both improved functional neurological outcomes and molecular correlates compared to only glyburide or hypothermia. At 24 hours post-occlusion, rats receiving combined glyburide and hypothermia treatment performed significantly better on the median modified neurological severity score compared to glyburide treatment at 6 hours. ${ }^{45}$ The dual treatments at 6 hours post-occlusion also lowered molecular markers of inflammation including cyclooxygenase- 2 , tumor necrosis factor (TNF)- $\alpha$ and interleukin- $1 \beta$ more than either glyburide alone or hypothermia. Taken together, these observations on dual treatment show a novel promising synergy of two well-documented treatments.

\section{Difficulties associated with rat models of stroke}

One caveat to all the evidences presented above is that all of the rat stroke model experiments were performed using young male rats. ${ }^{55}$ Age-based differences in both stroke mechanisms and risk factors have been well documented in humans. ${ }^{56}$ In animal models, the age-related changes are less clear, but still have tended to show worse overall recovery in older animals. ${ }^{55,57}$ These age differences may account, in part, for the historical difficulty of translating promising preclinical evidence to effective clinical stroke treatments.

\section{$\mathrm{K}_{\text {ATP }}$ channels and neuronal protection}

In the foregoing work, it was assumed that glyburide exerts its protective effects during brain injury by targeting newly upregulated SUR1-TRPM4 channels. However, glyburide also may affect $\mathrm{K}_{\mathrm{ATP}}$ channels, which are constitutively expressed under normal conditions by some neurons and microglia. ${ }^{22,23}$ In two studies, glyburide was protective under ischemic conditions and likely did not target SUR1-TRPM4 because, as detailed previously, SUR1-TRPM4 channels are not observed until several hours after ischemia onset. ${ }^{16}$

Wistar rats were exposed to ischemia for 15 minutes followed by a relatively short (1 hour) reperfusion time. ${ }^{43}$
These rats had been infused before ischemia with either glyburide or saline. Saline-treated animals exhibited greatly increased proinflammatory markers, including TNF- $\alpha$ and neutrophil recruitment, as well as decreased anti-inflammatory markers such as interleukin-10. Glyburide-treated animals did not have any of these changes. A possible explanation could be that glyburide lessens secondary injury by reducing neutrophil recruitment, which has been observed in other organs and tissues. ${ }^{58-61}$

An in vitro model of ischemia utilized hippocampal slices exposed to prolonged oxygen deprivation. ${ }^{62}$ Bathing these tissues in glyburide before and during ischemia prevented the field loss and neuronal death usually associated with in vitro ischemia.

Liu et al conducted similar studies that directly targeted the $\mathrm{K}_{\text {ATP }}$ channel in a mouse model of ischemia. ${ }^{63}$ The authors found that mice undergoing permanent MCAo, when pretreated with diazoxide, a $\mathrm{K}_{\text {ATP }}$ channel opener, had much smaller infarct volumes $(25.0 ; P<0.05)$ than mice pretreated with tolbutamide, a $\mathrm{K}_{\mathrm{ATP}}$ channel inhibitor $(52.9 ; P<0.05)$. These findings lend credence to the idea that $\mathrm{K}_{\mathrm{ATP}}$ channels may be an important therapeutic target in stroke research. However, the effects, if any, that glyburide exerts on $\mathrm{K}_{\text {ATP }}$ channels remain unclear.

\section{Glyburide and microglia}

A number of studies have postulated that glyburide influences microglial $\mathrm{K}_{\mathrm{ATP}}$ to improve outcomes in cerebral ischemia. ${ }^{38,64,65}$ In a study by Ortega et al, transformed microglia exposed to the proinflammatory ligands, lipopolysaccharide and interferon $\gamma$, increased transcription and translation of Sur1, Kir6.1 and Kir6.2, the subunits that form $\mathrm{K}_{\text {ATP }}$ channels. When microglia were exposed to the proinflammatory agents in the presence of glyburide, they increased their capacity to consume necrotic tissue and release the proinflammatory cytokine, TNF- $\alpha .{ }^{38}$ From this, the authors concluded that at least a portion of glyburide's protective effects after ischemia were due to $\mathrm{K}_{\mathrm{ATP}}$ channel inhibition.

A recent study by Kurland et al examined the protective effects of glyburide by studying rat microglia in vivo and vitro as well as N9 microglia. ${ }^{18}$ They activated toll-like receptor 4 (TLR4) using lipopolysaccharide, similar to the Ortega et al study. In cultured rat microglia, TLR4 activation led to an upregulation of mRNA for both Sur1 and Trpm4, but not Kir6.2. These mRNA results were partially replicated in N9 microglia. However, both microglial lines showed an increased co-association of Sur1 and Trpm4 and no increase in $\mathrm{K}_{\mathrm{ATP}}$ (Sur1-Kir6.2) after TLR4 activation, 


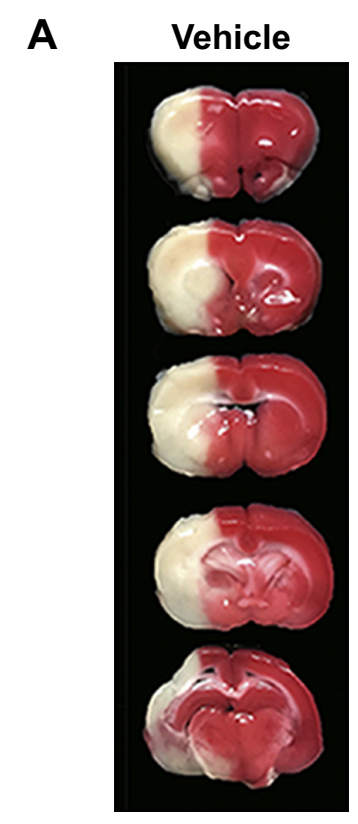

B
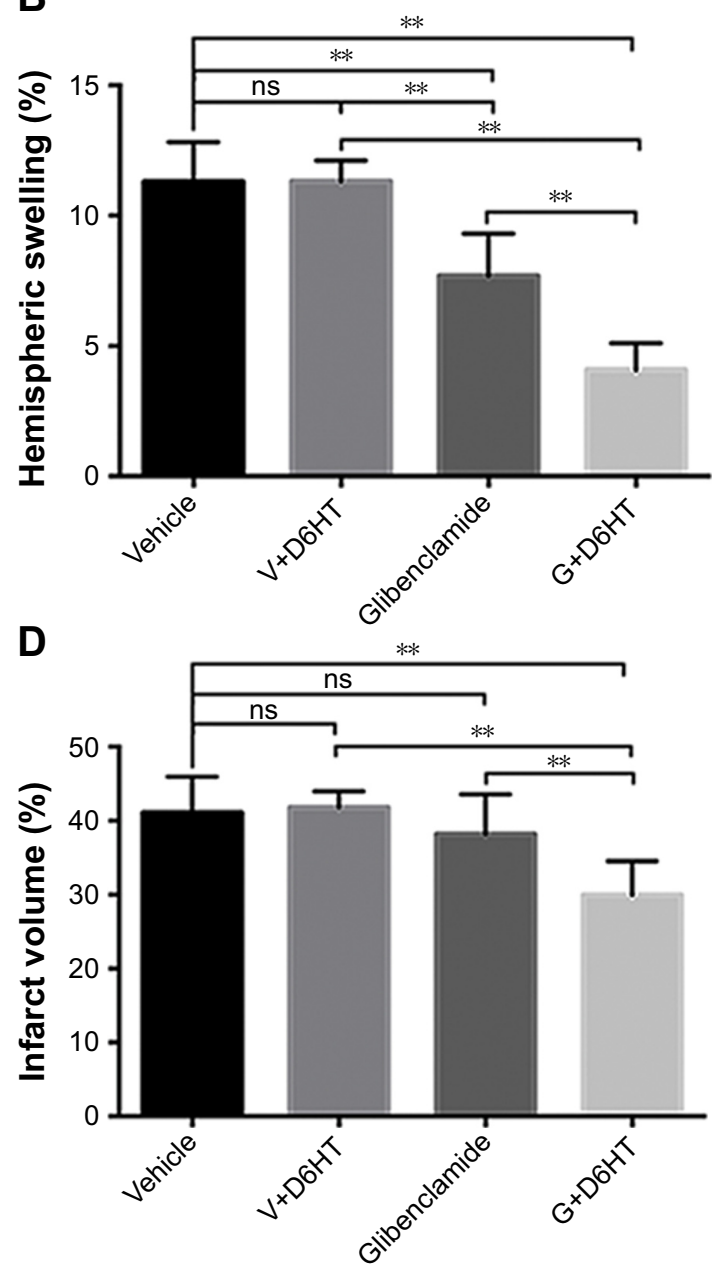

V+D6HT Glibenclamide

G+D6HT
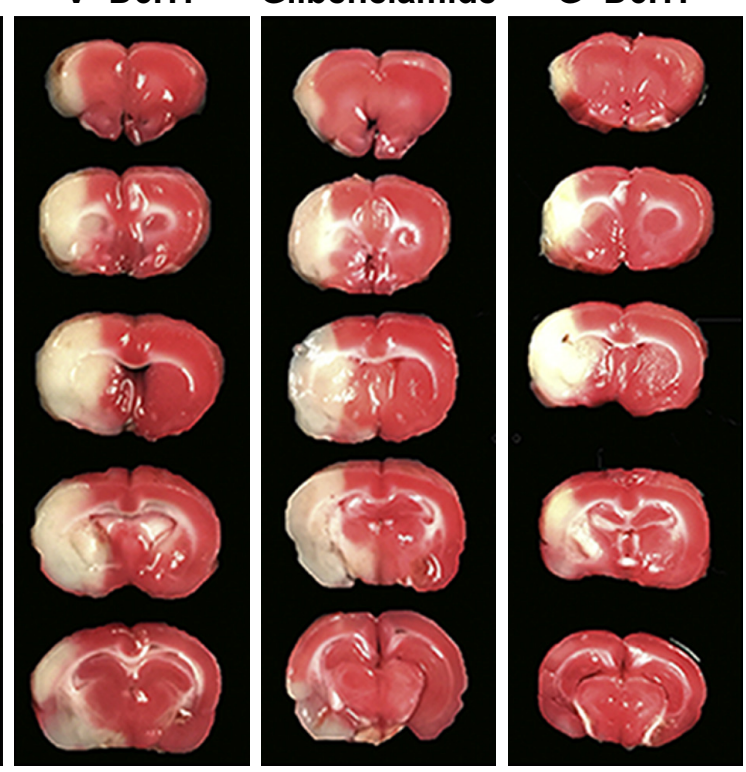

C

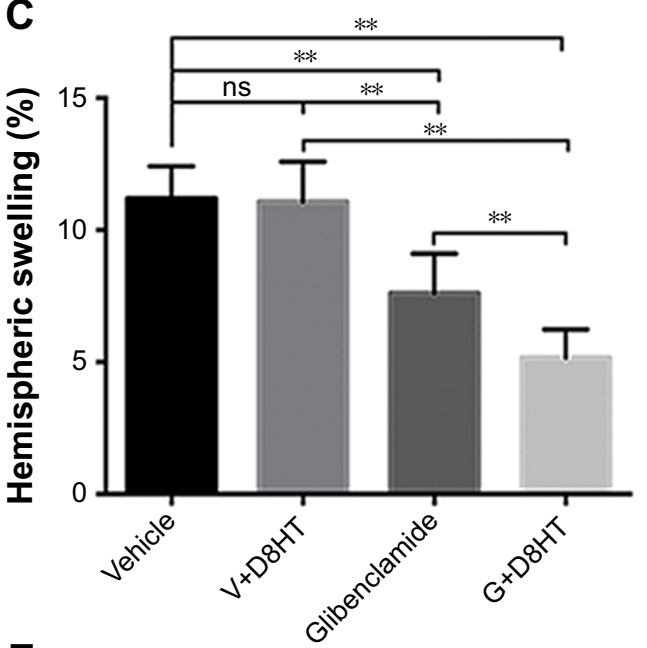

E

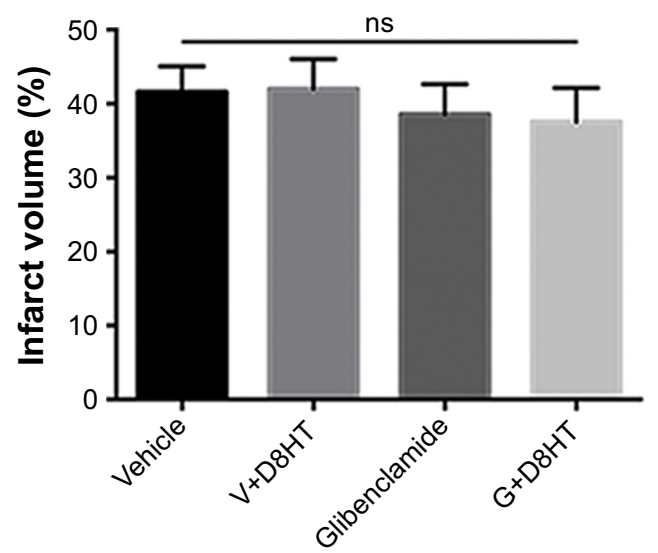

Figure 2 Glyburide extends the therapeutic window for hypothermia and enhances its ability to attenuate cerebral edema and decrease infarct volume.

Notes: Rats were subjected to hypothermia or not at 6 or 8 hours after ischemia onset and rewarmed slowly at $0.5^{\circ} \mathrm{C} / \mathrm{h}$. (A) Representative triphenyltetrazolium chloridestained coronal sections of rat brains at 24 hours after MCAo with treatments begun at 6 hours, as indicated, for vehicle only, vehicle combined with hypothermia at 6 hours after ischemia onset (V+D6HT), glyburide only, or glyburide with hypothermia at 6 hours after ischemia onset (G+D6HT). (B, C) Hemispheric swelling was compared among animals treated at 6 hours (B) or 8 hours (C). (D, E) Infarct volume was compared among animals treated at 6 hours (D) or 8 hours (E); $* * P<0.01$. Copyright $(2) 2003$. Europe PMC. Adapted from Wu Z, Zhu SZ, Hu YF, et al. Glibenclamide enhances the effects of delayed hypothermia after experimental stroke in rats. Brain Res. 20I6; I643:I I3-I22.45 Abbreviations: MCAo, middle cerebral artery occlusion; ns, no significance. 
indicating that TLR4 activation causes de novo upregulation of SUR1-TRPM4.

In the aforementioned study, blockade of newly expressed SUR1-TRPM4 channels with glyburide decreased nuclear translocation of nuclear factor of activated $\mathrm{T}$ cells, a transcription factor that regulates the expression of numerous proinflammatory cytokines and chemokines as well as of nitric oxide synthase 2. The authors hypothesized that blocking the SUR1TRPM4 channel caused an increase in intracellular calcium, which, in turn, activated $\mathrm{Ca} 2+/$ calmodulin-dependent kinase II, whose downstream effectors caused a decrease in phosphorylation of nuclear factor of activated T cells, and thus a decrease in nuclear translocation of the transcription factor. This hypothesis was supported by evidence of increased activated $\mathrm{Ca} 2+/$ calmodulin-dependent kinase II in glyburide-treated microglia. ${ }^{18}$ The authors hypothesize that this mechanism is responsible, in part, for glyburide's protective effects on microglia.

\section{Other potential clinical targets of glyburide}

Though not the specific focus of this review, glyburide has shown potential to treat other brain injuries including traumatic brain injury (TBI). Multiple studies have shown that treatment of glyburide reduces the swelling and edema often associated with TBI in animal models. ${ }^{66-69}$

Early clinical findings have also been promising. Khalili et al conducted a single-center double-blind study with both moderate (Glasgow Coma Scale [GCS] score 9-12) and severe (GCS score 5-8) TBI patients. ${ }^{70}$ The study included 64 patients, and it was found that glyburide significantly lowered edema expansion ratios from baseline to day 3 $(P<0.001)$ and from baseline to day $7(P=0.003)$ compared to the placebo group. However, the study found no difference in long-term outcomes between the two groups.

A second study by Zafardoost et al examined glyburide treatment in TBI patients presenting with diffuse axonal injury. ${ }^{85}$ The single-center, randomized controlled trial included 40 patients with both moderate and severe TBI. Patients treated with glyburide had a significantly better GCS at discharge than controls ( 13.9 vs $11.5 ; P=0.004)$. However, this study was limited by a lack of long-term follow-up.

Both studies, although promising, had limitations both in outcome measures and sample size. Regardless, glyburide has shown promise in the treatment of TBI and warrants further investigation.

\section{Retrospective studies in humans with stroke}

Kunte et al performed an analysis of diabetic stroke patients who were continued on glyburide or another second-generation sulfonylurea after stroke. ${ }^{71}$ They worked with a dataset that had been examined previously by Weih et al, in which the authors examined the question whether sulfonylureas impart an increased risk for stroke or stroke severity, which it did not. ${ }^{72}$ The patients examined were limited to those arriving at hospital within 24 hours of stroke onset. When comparing patients who were continued on a sulfonylurea vs those who were on a different diabetes medication, $36 \%$ of patients who continued on a sulfonylurea had at least a four-point decrease in the National Institutes of Health stroke scale (NIHSS) from admission to discharge or a discharge NIHSS of 0 , compared to just $7 \%$ in controls (odds ratio $=7.4,95 \%$ CI $1.5-37 ; P=0.007$ ). The secondary outcome, the percent of patients achieving functional independence, defined as modified Rankin score $(\mathrm{mRS}) \leq 2$, was found in $82 \%$ of patients who continued on a sulfonylurea vs $57 \%$ in the control group (odds ratio $=3.4$, $95 \%$ CI 1.1-11; $P=0.035)$. The only difference in baseline characteristic observed was a difference in stroke subtype.

Kunte et al replicated this analysis in another cohort of diabetic patients presenting with stroke to Charité hospital from January 2005 to December $2006 .^{29}$ The control group (177 subjects) was compared to those who continued on a sulfonylurea (43 subjects). The authors examined the same outcomes as in the prior study, and in addition, looked at rates of hemorrhagic transformation and in-hospital death. Patients treated with a sulfonylurea experienced significantly better outcomes across all measures, including in-hospital death $(0 \%$ vs $10 \% ; P=0.027)$ and hemorrhagic transformation ( $0 \%$ vs $11 \% ; P=0.016)$. These results remained significant after adjusting for baseline differences.

\section{Injectable glyburide (RP- I | 27)}

The formulation of gyburide used to treat diabetes is an oral one. However, for the treatment of stroke, oral administration is undesirable because episodic oral administration of drug leads to high peak serum levels that reach a maximum 1-2 hours after ingestion, followed by low serum levels. Non-diabetic patients taking oral glyburide are at risk for hypoglycemia because of these spikes and the insulin reaction they provoke. Also, bioavailability of drug taken orally depends on stomach $\mathrm{pH}$, which may vary, especially in sick patients. Thus, a non-oral formulation, preferably an IV one, is required.

IV administration allows for a constant serum level of glyburide, which lessens the risk of hypoglycemia in nondiabetic patients. IV administration reaches therapeutic levels more quickly, a paramount issue in stroke patients where delays in treatment may translate into permanent neuronal loss. Moreover, the promising findings in preclinical 
models were obtained with a constant subcutaneous infusion of glyburide, ${ }^{17,26,41,42}$ which pharmacokinetically resembles constant IV infusion. Episodic delivery of drug, although promising, failed to generate similar results. ${ }^{38,73}$

\section{Phase I clinical trial of RP- I I 27 in normal volunteers}

A Phase I study of RP-1127 (ClinicalTrials.gov identifier: NCT01132703) was conducted in normal volunteers to examine the safety and tolerability of intravenous glyburide RP-1127 administered as a bolus dose followed by a 72-hour continuous infusion.

The study had four arms: one placebo and three different doses of RP-1127 of 3, 6 or $10 \mathrm{mg} /$ day. The trial reported no serious adverse events. The $3 \mathrm{mg} /$ day group did show lower blood glucose levels than placebo, but these did not reach levels of hypoglycemia $(<70 \mathrm{mg} / \mathrm{dL}){ }^{74-76}$

In each of the other two groups, one subject was discontinued because of persistent hypoglycemia. As such, $3 \mathrm{mg} /$ day was chosen for later studies of RP-1127 as the one that resulted in the mildest decrease in blood glucose levels while still achieving concentrations which, based on preclinical work, were likely to be therapeutic.

\section{Phase lla prospective, open-label, multicenter clinical trial of RP- I I 27}

Subjects with large hemispheric infarctions were enrolled prospectively in a Phase IIa study of RP-1127 entitled GAMES-Pilot (Glyburide Advantage in Malignant Edema and Stroke; ClinicalTrials.gov: NCT01268683). The primary outcomes of the study were recruitment feasibility and management of blood glucose levels. The secondary objectives included safety and tolerability information on RP-1127, as well as clinical and outcome data for comparison with historical controls.

Subjects with an acute ischemic stroke enrolled in the trial met the inclusion criteria including age $18-80$ years, baseline diffusion-weighted imaging (DWI) lesion volume of $82-210 \mathrm{~cm}^{3}$ and start of study drug infusion within 10 hours after symptom onset. Notable exclusion criteria were thrombectomy, cases requiring decompressive craniectomy prior to enrollment and admission blood glucose $<55 \mathrm{mg} / \mathrm{dL}$.

Of the ten subjects enrolled, two had serious adverse events; both required decompressive craniectomy and one died. These events were considered to be unrelated to the study drug. ${ }^{77}$ The drug was well tolerated with no safety concerns or hypoglycemia. Although subjects did experience a decline in serum glucose levels, the decreases were comparable to levels reported in prior trials involving acute stroke patients. ${ }^{76}$
A secondary analysis compared the ten subjects against matched historical controls. Serial magnetic resonance imaging scans were analyzed for both apparent diffusion coefficient (ADC) and fluid-attenuated inversion recovery (FLAIR) signals, sensitive markers of early cytotoxic edema and later vasogenic edema in stroke. ${ }^{78,79}$ During the first 24 hours post-stroke, RP-1127 and historical controls had identical T2 FLAIR signaling and ADC - RP-1127 treatment did not affect markers of early cytotoxic edema.

However, both ADC and T2 FLAIR signals were significantly different at all time points after 24 hours (Figure 3 ), indicating that RP-1127 attenuates vasogenic edema formation in stroke patients. Additionally, RP-1127 affected FLAIR ratio in a dose-dependent manner (Figure 3).

The analysis further looked at the levels of MMP-9, a protein upregulated following stroke that is associated with vasogenic edema. ${ }^{80,81}$ The levels of MMP-9 in subjects treated with RP-1127 (54 $\pm 17 \mathrm{ng} / \mathrm{mL})$ were significantly lower than in historical controls $(212 \pm 151 \mathrm{ng} / \mathrm{mL}){ }^{82}$ Together, these findings corroborated preclinical work indicating that RP-1127 modifies the profile of vasogenic edema.

Another post hoc analysis examined 90-day outcomes in these ten subjects compared to historical controls. ${ }^{83}$ Study subjects were matched with historical controls using Euclidean matching. Overall, GAMES-Pilot subjects had similar baseline NIHSS scores, larger DWI volumes on magnetic resonance imaging and were younger than matched controls. ${ }^{83}$ At 3 months, subjects receiving RP-1127 had significantly higher rates of good outcomes, defined as $\mathrm{mRS}$ $0-4$, compared to controls ( $90 \%$ vs 50\%; $P=0.049)$. This trend persisted, but was not statistically significant when good outcomes were defined as mRS $0-3(40 \%$ vs $25 \% ; P=0.43)$.

\section{Phase II double-blind, randomized, placebo-controlled, multicenter clinical trial of RP-I I 27}

Subjects with large hemispheric infarctions were enrolled in a Phase II study of RP-1127 entitled GAMES-RP (ClinicalTrials. gov: NCT01794182). The study prospectively enrolled 86 subjects, aged $18-80$ years, presenting within 10 hours of symptom onset, with a large anterior circulation infarction and DWI lesions of 82-300 $\mathrm{cm}^{3}$. Enrollment was terminated early because of funding considerations. The prespecified primary outcome was the proportion of subjects with an $\mathrm{mRS} \leq 4$ at 90 days without decompressive craniectomy. ${ }^{84}$

At 90 days, the percentage of subjects achieving the primary outcome was the same between those treated with RP-1127 (41\%) and controls (39\%). The analysis of mRS shift trended toward significance $(P=0.12)$, and the Kaplan-Meier 
A
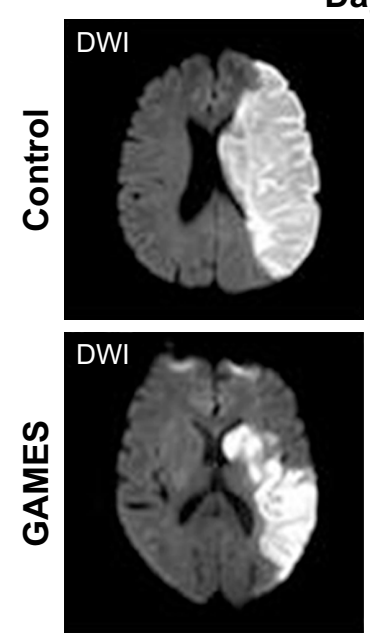

Day 2
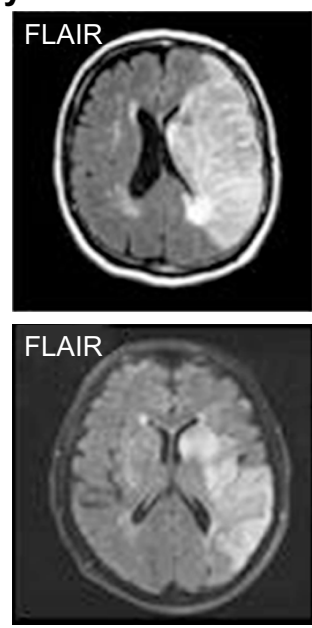

C

FLAIR ratio in gray and white matter

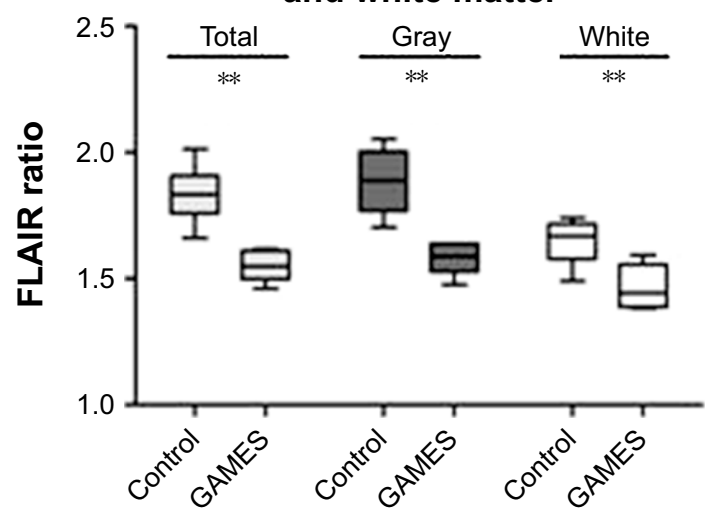

B

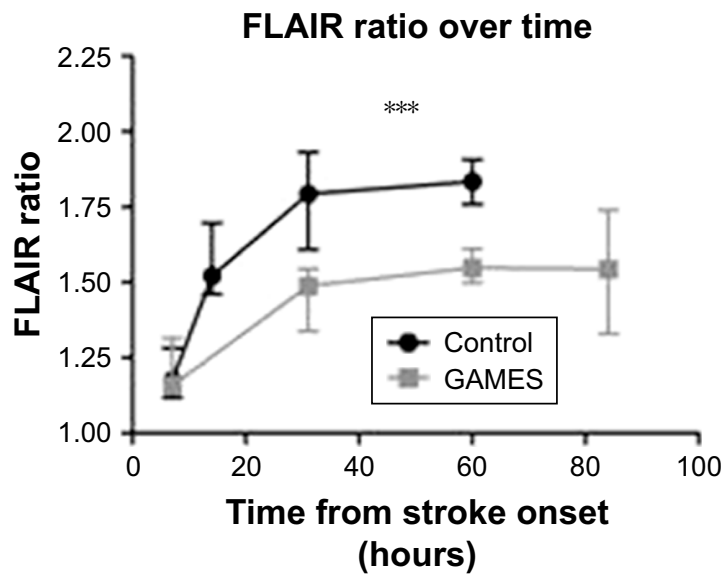

D

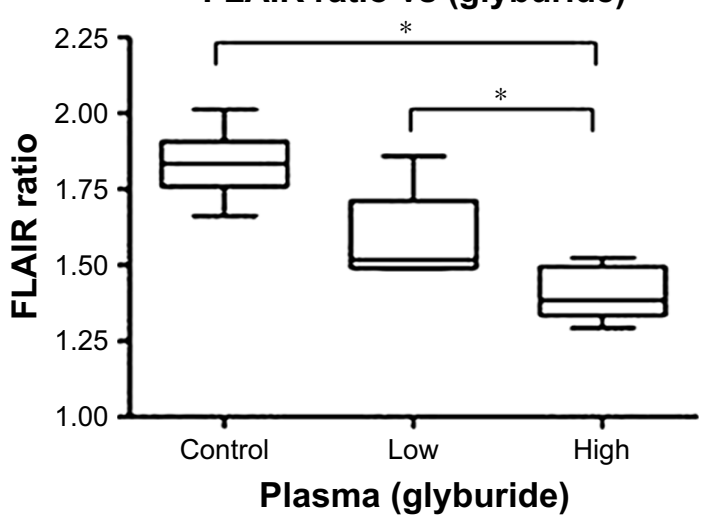

Figure 3 Vasogenic edema on T2 FLAIR is attenuated by glyburide treatment in human stroke.

Notes: (A) Representative examples of DWI (left) and FLAIR sequences (right) from a control subject (top panels) and an RP-I I 27-treated subject (bottom panels); MRI scans were obtained at day 2 from the onset of stroke. (B) Quantitative analysis of the FLAIR ratio in control and GAMES-Pilot subjects shows a reduced FLAIR ratio with RP-I I 27 treatment; ${ }^{* * * P}<0.005$ by repeated measures MANOVA. (C) Segmentation of the stroke lesions demonstrates an equivalent effect of RP-I I 27 on both gray and white matter regions; $* * P<0.0$ I. (D) The plasma concentration of glyburide correlates with FLAIR ratio intensity in the GAMES-Pilot subjects; $* P<0.01$. Reprinted by permission from Springer Nature: Neurocrit Care. Glyburide is associated with attenuated vasogenic edema in stroke patients. Kimberly WT, Battey TW, Pham L, et al. 20I4;20(2): 193-20I.82 Abbreviations: DWI, diffusion-weighted imaging; FLAIR, fluid-attenuated inversion recovery; MANOVA, multivariate analysis of variance; MRI, magnetic resonance imaging.

survival curve showed a trend toward better survival with RP-1127 compared to control ( $P=0.06$; Figure 4).

The trial also examined safety concerns, which had not been examined previously in a prospective randomized trial. Serious adverse event rates were nearly identical between the control (72\%) and RP-1127 (68\%) arms of the trial. The RP-1127 group had more instances of hypoglycemia, defined at blood glucose $<3.1 \mathrm{mmol} / \mathrm{L}$, but of these only one was considered severe and all were readily treated using a prespecified hypoglycemia protocol.

This study also examined the effect of RP-1127 on midline shift and plasma levels of MMP-9. Midline shift at 72-96 hours, an established marker of brain swelling, was significantly reduced in RP-1127 subjects vs controls (4.6 vs $8.5 \mathrm{~mm}$; $P=0.0006)$. This corroborated preclinical data that glyburide reduces swelling associated with large hemispheric infarction and malignant edema. ${ }^{17}$ This study also found that average plasma levels of MMP-9 at 24-72 hours were significantly different (211 vs $346 \mathrm{ng} / \mathrm{mL} ; P=0.006$ ) between the groups.

Overall, the GAMES-RP study confirmed prior findings that glyburide is safe and well tolerated in acutely ill patients with stroke. The primary efficacy outcome, although disappointing, was mitigated, in part, by the promising data on midline shift, plasma MMP-9, functional outcome and survival, which will serve to guide an upcoming Phase III trial.

\section{Conclusion}

Recent advances in molecular neurobiology have broadened our understanding of the role of the SUR1-TRPM4 channel in acute focal cerebral ischemia. In all species investigated to date, including those with lissencephalic as well as gyrencephalic brains, focal cerebral ischemia is marked by 

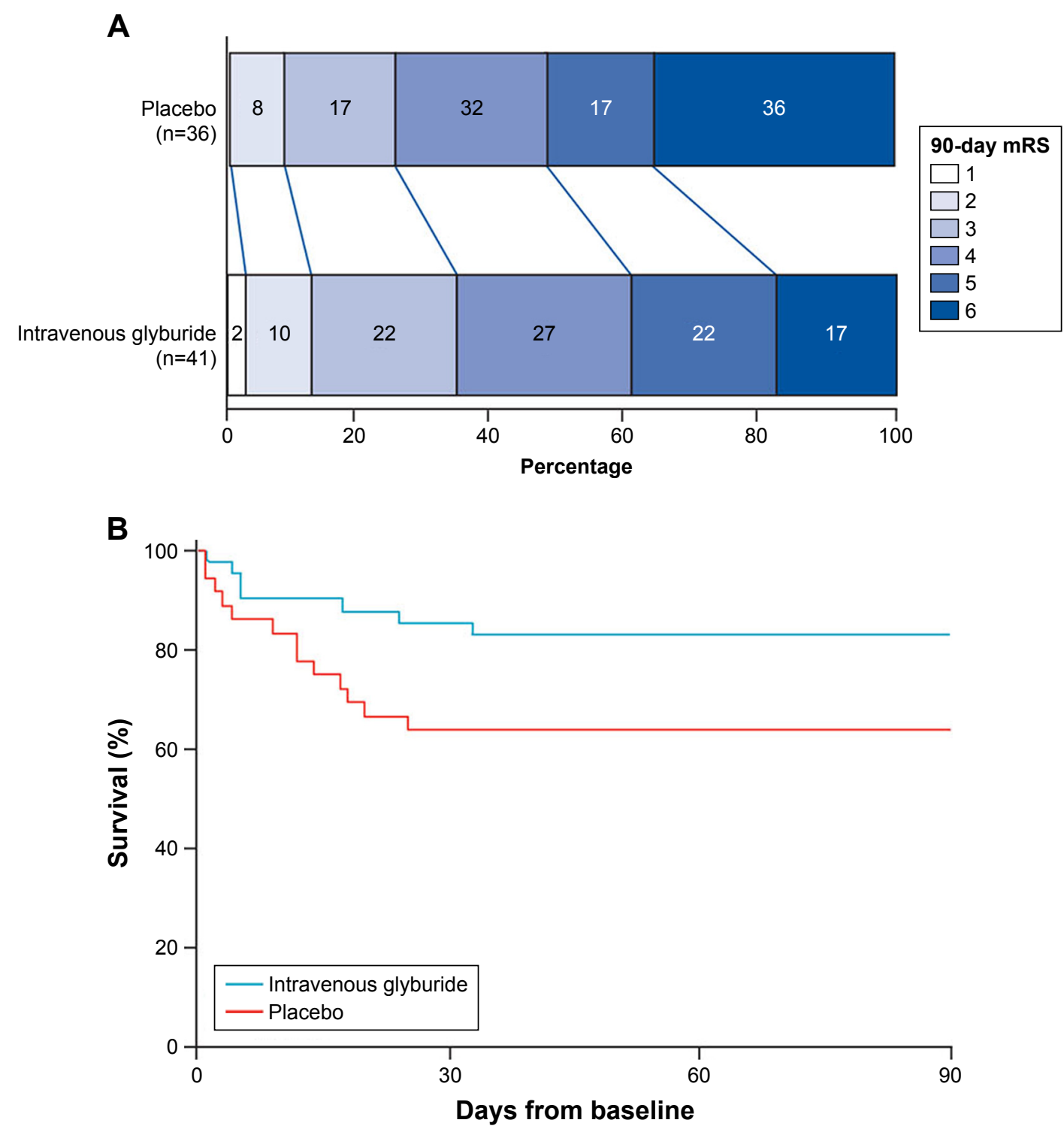

Enrolled 7 days 14 days 30 days

$90 \pm 7$ days

Events (cumulative)

Intravenous glyburide

Placebo

Number at risk

Intravenous glyburide

Placebo

$\begin{array}{llll}. . & 4 & 4 & 6 \\ . . & 5 & 9 & 13 \\ & & & \\ 41 & 37 & 37 & 35 \\ 36 & 31 & 27 & 23\end{array}$

627

$13-13$

$\begin{array}{llll}31 & 27 & 23 & 23\end{array}$

Figure 4 Secondary clinical outcomes in the glyburide and placebo groups in GAMES-RP.

Notes: (A) Distribution of mRS scores in the per-protocol sample at 90 days. (B) Kaplan-Meier survival curve for each treatment group. Reprinted from The Lancet, I5(I I), Sheth KN, Elm JJ, Molyneaux BJ, et al. Safety and efficacy of intravenous glyburide on brain swelling after large hemispheric infarction (GAMES-RP): a randomised, double-blind, placebo-controlled phase 2 trial, Pages No. II60-II69, Copyright (2016), with permission from Elsevier. ${ }^{84}$

Abbreviation: $\mathrm{mRS}$, modified Rankin score.

upregulation of SUR1-TRPM4 in the various cell types of the neurovascular unit. At a cellular level, SUR1-TRPM4 channels play critical roles in oncotic cell swelling, necrotic (oncotic) cell death, Aqp4-mediated swelling of astrocytes and rtPA-induced MMP-9 secretion by endothelial cells. Given these effects at a cellular level, it is unsurprising that blockade of SUR1-TRPM4 in vivo in preclinical models of stroke lessens microvascular dysfunction, reduces edema formation and brain swelling, ameliorates hemorrhagic transformation, improves functional outcome and reduces mortality. Growing evidence from clinical trials supports the concept that SUR1-TRPM4 blockade by glyburide may be beneficial in humans with stroke, specifically those with large hemispheric infarction, in whom promising findings 
have been made with regard to brain swelling (midline shift), MMP-9, functional outcomes and mortality.

\section{Acknowledgments}

JMS is supported by grants from the Department of Veterans Affairs (I01BX002889), the Department of Defense (SCI170199), the National Heart, Lung and Blood Institute (R01HL082517) and the National Institute of Neurological Disorders and Stroke (NINDS) (R01NS060801; R01NS102589; R01NS105633).

\section{Disclosure}

JMS holds a US patent (7,285,574), "A novel non-selective cation channel in neural cells and methods for treating brain swelling." JMS is a member of the Board of Directors and holds shares in Remedy Pharmaceuticals, and is a paid consultant for Biogen. No support, direct or indirect, was provided to JMS, or for this project, by Remedy Pharmaceuticals or by Biogen. The authors report no other conflicts of interest in this work.

\section{References}

1. Benjamin EJ, Blaha MJ, Chiuve SE, et al. Heart disease and stroke statistics - 2017 update. Circulation. 2017;135(10):e146-e603.

2. Hacke W, Schwab S, Horn M, Spranger M, de Georgia M, von Kummer R, von KR. 'Malignant' middle cerebral artery territory infarction: clinical course and prognostic signs. Arch Neurol. 1996;53(4): 309-315.

3. Berrouschot J, Sterker M, Bettin S, Köster J, Schneider D. Mortality of space-occupying ('malignant') middle cerebral artery infarction under conservative intensive care. Intensive Care Med. 1998;24(6): 620-623.

4. Adeoye O, Hornung R, Khatri P, Kleindorfer D. Recombinant tissuetype plasminogen activator use for ischemic stroke in the United States. Stroke J Cereb Circ. 2011;42(7):1952-1955.

5. Kleindorfer D, Lindsell CJ, Brass L, Koroshetz W, Broderick JP. National US estimates of recombinant tissue plasminogen activator use: ICD-9 codes substantially underestimate. Stroke. 2008;39(3):924-928.

6. Singer OC, Hamann GF, Misselwitz B, Steinmetz H, Foerch C. Arbeitsgruppe Schlaganfall Hessen. Time trends in systemic thrombolysis in a large hospital-based stroke registry. Cerebrovasc Dis. 2012; 33(4):316-321.

7. Jauss M, Schütz HJ, Tanislav C, Misselwitz B, Rosenow F. Effect of daytime, weekday and year of admission on outcome in acute ischaemic stroke patients treated with thrombolytic therapy. Eur J Neurol. 2010; 17(4):555-561.

8. Kurland DB, Khaladj-Ghom A, Stokum JA, et al. Complications associated with decompressive craniectomy: a systematic review. Neurocrit Care. 2015;23(2):292-304.

9. Bryan J, Muñoz A, Zhang X, et al. ABCC8 and ABCC9: ABC transporters that regulate K+ channels. Pflugers Arch. 2007;453(5):703-718.

10. Burke MA, Mutharasan RK, Ardehali H. The sulfonylurea receptor, an atypical ATP-binding cassette protein, and its regulation of the KATP channel. Circ Res. 2008;102(2):164-176.

11. Aittoniemi J, Fotinou C, Craig TJ, de Wet H, Proks P, Ashcroft FM. Review. SUR1: a unique ATP-binding cassette protein that functions as an ion channel regulator. Philos Trans R Soc Lond B Biol Sci. 2009; 364(1514):257-267.
12. Woo SK, Kwon MS, Ivanov A, Gerzanich V, Simard JM. The sulfonylurea receptor 1 (Sur1)-transient receptor potential melastatin 4 (Trpm4) channel. J Biol Chem. 2013;288(5):3655-3667.

13. Yamada K, Inagaki N. Neuroprotection by KATP channels. J Mol Cell Cardiol. 2005;38(6):945-949.

14. Simard JM, Woo SK, Schwartzbauer GT, Gerzanich V. Sulfonylurea receptor 1 in central nervous system injury: a focused review. J Cereb Blood Flow Metab. 2012;32(9):1699-1717.

15. Simard JM, Woo SK, Gerzanich V. Transient receptor potential melastatin 4 and cell death. Pflugers Arch. 2012;464(6):573-582.

16. Simard JM, Chen M, Tarasov KV, et al. Newly expressed SUR1regulated $\mathrm{NC}(\mathrm{Ca}-\mathrm{ATP})$ channel mediates cerebral edema after ischemic stroke. Nat Med. 2006;12(4):433-440.

17. Simard JM, Tsymbalyuk N, Tsymbalyuk O, Ivanova S, Yurovsky V, Gerzanich V. Glibenclamide is superior to decompressive craniectomy in a rat model of malignant stroke. Stroke. 2010;41(3):531-537.

18. Kurland DB, Gerzanich V, Karimy JK, et al. The Sur1-Trpm4 channel regulates NOS2 transcription in TLR4-activated microglia. J Neuroinflammation. 2016;13(1):130.

19. Mehta RI, Ivanova S, Tosun C, Castellani RJ, Gerzanich V, Simard JM. Sulfonylurea receptor 1 expression in human cerebral infarcts. J Neuropathol Exp Neurol. 2013;72(9):871-883.

20. Mehta RI, Tosun C, Ivanova S, et al. Sur1-Trpm4 cation channel expression in human cerebral infarcts. J Neuropathol Exp Neurol. 2015; 74(8):835-849.

21. Loh KP, Ng G, Yu CY, et al. TRPM4 inhibition promotes angiogenesis after ischemic stroke. Pflugers Arch. 2014;466(3):563-576.

22. Liss B, Roeper J. Molecular physiology of neuronal K-ATP channels (review). Mol Membr Biol. 2001;18(2):117-127.

23. Pelletier MR, Pahapill PA, Pennefather PS, Carlen PL. Analysis of single K(ATP) channels in mammalian dentate gyrus granule cells. J Neurophysiol. 2000;84(5):2291-2301.

24. Sullivan HC, Harik SI. ATP-sensitive potassium channels are not expressed in brain microvessels. Brain Res. 1993;612(1-2):336-338.

25. Woo SK, Kwon MS, Geng Z, et al. Sequential activation of hypoxiainducible factor 1 and specificity protein 1 is required for hypoxiainduced transcriptional stimulation of Abcc8. J Cereb Blood Flow Metab. 2012;32(3):525-536.

26. Simard JM, Woo SK, Tsymbalyuk N, et al. Glibenclamide-10-h treatment window in a clinically relevant model of stroke. Transl Stroke Res. 2012;3(2):286-295.

27. Chen B, Ng G, Gao Y, et al. Non-invasive multimodality imaging directly shows TRPM4 inhibition ameliorates stroke reperfusion injury. Transl Stroke Res. Epub 2018 Mar 22.

28. Arikan F, Martínez-Valverde T, Sánchez-Guerrero Ángela, et al. Malignant infarction of the middle cerebral artery in a porcine model. A pilot study. PLoS One. 2017;12(2):e0172637.

29. Kunte H, Busch MA, Trostdorf K, et al. Hemorrhagic transformation of ischemic stroke in diabetics on sulfonylureas. Ann Neurol. 2012; 72(5):799-806.

30. Gerzanich V, Woo SK, Vennekens R, et al. De novo expression of Trpm4 initiates secondary hemorrhage in spinal cord injury. Nat Med. 2009;15(2):185-191.

31. Bano D, Nicotera P. Ca2+ signals and neuronal death in brain ischemia. Stroke. 2007;38(2 Suppl):674-676.

32. Arundine M, Tymianski M. Molecular mechanisms of calciumdependent neurodegeneration in excitotoxicity. Cell Calcium. 2003; 34(4-5):325-337.

33. Chen M, Dong Y, Simard JM. Functional coupling between sulfonylurea receptor type 1 and a nonselective cation channel in reactive astrocytes from adult rat brain. $J$ Neurosci. 2003;23(24):8568-8577.

34. Simard JM, Woo SK, Bhatta S, Gerzanich V. Drugs acting on SUR1 to treat CNS ischemia and trauma. Curr Opin Pharmacol. 2008;8(1): 42-49.

35. Findlay I. Effects of $\mathrm{pH}$ upon the inhibition by sulphonylurea drugs of ATP-sensitive $\mathrm{K}+$ channels in cardiac muscle. J Pharmacol Exp Ther. 1992;262(1):71-79. 
36. Tomiyama Y, Brian JE, Todd MM. Cerebral blood flow during hemodilution and hypoxia in rats: role of ATP-sensitive potassium channels. Stroke. 1999;30(9):1942-1948.

37. Nedergaard M, Kraig RP, Tanabe J, Pulsinelli WA. Dynamics of interstitial and intracellular $\mathrm{pH}$ in evolving brain infarct. Am J Physiol. 1991;260(3 Pt 2):R581-R588.

38. Ortega FJ, Gimeno-Bayon J, Espinosa-Parrilla JF, et al. ATP-dependent potassium channel blockade strengthens microglial neuroprotection after hypoxia-ischemia in rats. Exp Neurol. 2012;235(1):282-296.

39. Simard JM, Kent TA, Chen M, Tarasov KV, Gerzanich V. Brain oedema in focal ischaemia: molecular pathophysiology and theoretical implications. Lancet Neurol. 2007;6(3):258-268.

40. Weiss N, Miller F, Cazaubon S, Couraud PO. The blood-brain barrier in brain homeostasis and neurological diseases. Biochim Biophys Acta. 2009;1788(4):842-857.

41. Simard JM, Yurovsky V, Tsymbalyuk N, Melnichenko L, Ivanova S, Gerzanich V. Protective effect of delayed treatment with low-dose glibenclamide in three models of ischemic stroke. Stroke. 2009;40(2):604-609.

42. Simard JM, Geng Z, Silver FL, et al. Does inhibiting Sur1 complement rt-PA in cerebral ischemia? Ann N Y Acad Sci. 2012;1268:95-107.

43. Abdallah DM, Nassar NN, Abd-El-Salam RM. Glibenclamide ameliorates ischemia-reperfusion injury via modulating oxidative stress and inflammatory mediators in the rat hippocampus. Brain Res. 2011;1385:257-262.

44. Wali B, Ishrat T, Atif F, Hua F, Stein DG, Sayeed I. Glibenclamide administration attenuates infarct volume, hemispheric swelling, and functional impairments following permanent focal cerebral ischemia in rats. Stroke Res Treat. 2012;2012:1-6.

45. Wu Z, Zhu SZ, Hu YF, et al. Glibenclamide enhances the effects of delayed hypothermia after experimental stroke in rats. Brain Res. 2016; 1643:113-122.

46. Badaut J, Fukuda AM, Jullienne A, Petry KG. Aquaporin and brain diseases. Biochim Biophys Acta. 2014;1840(5):1554-1565.

47. Verkman AS, Smith AJ, Phuan PW, Tradtrantip L, Anderson MO. The aquaporin-4 water channel as a potential drug target in neurological disorders. Expert Opin Ther Targets. 2017;21(12):1161-1170.

48. Stokum JA, Kwon MS, Woo SK, et al. SUR1-TRPM4 and AQP4 form a heteromultimeric complex that amplifies ion/water osmotic coupling and drives astrocyte swelling. Glia. 2018;66(1):108-125.

49. Gerzanich V, Kwon MS, Woo SK, Ivanov A, Simard JM. SUR1TRPM4 channel activation and phasic secretion of MMP-9 induced by tPA in brain endothelial cells. PLoS One. 2018;13(4):e0195526.

50. Dumitrascu OM, Lamb J, Lyden PD. Still cooling after all these years: meta-analysis of pre-clinical trials of therapeutic hypothermia for acute ischemic stroke. J Cereb Blood Flow Metab. 2016;36(7):1157-1164.

51. Lyden PD, Allgren RL, Ng K, et al. Intravascular Cooling in the Treatment of Stroke (ICTuS): early clinical experience. J Stroke Cerebrovasc Dis. 2005;14(3):107-114.

52. Lyden P, Hemmen T, Grotta J, et al. Results of the Intravascular Cooling in the Treatment of Acute Stroke 2 Trial (ICTuS-2). Stroke. 2016;47(12):2888-2895.

53. Wu TC, Grotta JC. Hypothermia for acute ischaemic stroke. Lancet Neurol. 2013;12(3):275-284.

54. de Georgia MA, Krieger DW, Abou-Chebl A, et al. Cooling for Acute Ischemic Brain Damage (COOL AID): a feasibility trial of endovascular cooling. Neurology. 2004;63(2):312-317.

55. Liu F, Mccullough LD. Middle cerebral artery occlusion model in rodents: methods and potential pitfalls. J Biomed Biotechnol. 2011;2011:1-9.

56. Lucke-Wold BP, Logsdon AF, Turner RC, Rosen CL, Huber JD. Aging, the metabolic syndrome, and ischemic stroke: redefining the approach for studying the blood-brain barrier in a complex neurological disease. Adv Pharmacol San Diego Calif. 2014;71:411-449.

57. Liu F, Yuan R, Benashski SE, Mccullough LD. Changes in experimental stroke outcome across the life span. J Cereb Blood Flow Metab. 2009; 29(4):792-802.

58. Figura M, Chilton L, Liacini A, et al. Blockade of K(ATP) channels reduces endothelial hyperpolarization and leukocyte recruitment upon reperfusion after hypoxia. Am J Transplant. 2009;9(4):687-696.
59. da Silva-Santos JE, Santos-Silva MC, Cunha FQ, Assreuy J. The role of ATP-sensitive potassium channels in neutrophil migration and plasma exudation. J Pharmacol Exp Ther. 2002;300(3):946-951.

60. Pompermayer K, Amaral FA, Fagundes CT, et al. Effects of the treatment with glibenclamide, an ATP-sensitive potassium channel blocker, on intestinal ischemia and reperfusion injury. Eur J Pharmacol. 2007; 556(1-3):215-222.

61. Pompermayer K, Souza DG, Lara GG, et al. The ATP-sensitive potassium channel blocker glibenclamide prevents renal ischemia/reperfusion injury in rats. Kidney Int. 2005;67(5):1785-1796.

62. Nisticò R, Piccirilli S, Sebastianelli L, Nisticò G, Bernardi G, Mercuri NB. The blockade of $\mathrm{K}(+)$-ATP channels has neuroprotective effects in an in vitro model of brain ischemia. Int Rev Neurobiol. 2007;82:383-395.

63. Liu R, Wang H, Xu B, et al. Cerebrovascular safety of sulfonylureas: the role of KATP channels in neuroprotection and the risk of stroke in patients with type 2 diabetes. Diabetes. 2016;65(9):2795-2809.

64. Ortega FJ, Jolkkonen J, Mahy N, Rodríguez MJ. Glibenclamide enhances neurogenesis and improves long-term functional recovery after transient focal cerebral ischemia. J Cereb Blood Flow Metab. 2013; 33(3):356-364.

65. Ortega FJ, Jolkkonen J, Rodríguez MJ. Microglia is an active player in how glibenclamide improves stroke outcome. J Cereb Blood Flow Metab. 2013;33(7):1138-1139.

66. Patel AD, Gerzanich V, Geng Z, Simard JM. Glibenclamide reduces hippocampal injury and preserves rapid spatial learning in a model of traumatic brain injury. J Neuropathol Exp Neurol. 2010;69(12): 1177-1190.

67. Xu ZM, Yuan F, Liu YL, Ding J, Tian HL. Glibenclamide attenuates blood-brain barrier disruption in adult mice after traumatic brain injury. J Neurotrauma. 2017;34(4):925-933.

68. Stokum JA, Keledjian K, Hayman E, et al. Glibenclamide pretreatment protects against chronic memory dysfunction and glial activation in rat cranial blast traumatic brain injury. Behav Brain Res. 2017;333:43-53.

69. Simard JM, Kilbourne M, Tsymbalyuk O, et al. Key role of sulfonylurea receptor 1 in progressive secondary hemorrhage after brain contusion. J Neurotrauma. 2009;26(12):2257-2267.

70. Khalili H, Derakhshan N, Niakan A, et al. Effects of oral glibenclamide on brain contusion volume and functional outcome of patients with moderate and severe traumatic brain injuries: a randomized doubleblind placebo-controlled clinical trial. World Neurosurg. 2017;101: $130-136$.

71. Kunte H, Schmidt S, Eliasziw M, et al. Sulfonylureas improve outcome in patients with type 2 diabetes and acute ischemic stroke. Stroke. 2007; 38(9):2526-2530.

72. Weih M, Amberger N, Wegener S, Dirnagl U, Reuter T, Einhäupl K. Sulfonylurea drugs do not influence initial stroke severity and in-hospital outcome in stroke patients with diabetes. Stroke. 2001; 32(9):2029-2032.

73. Zhou Y, Fathali N, Lekic T, Tang J, Zhang JH. Glibenclamide improves neurological function in neonatal hypoxia-ischemia in rats. Brain Res. 2009;1270:131-139.

74. Gray CS, Hildreth AJ, Sandercock PA, et al. Glucose-potassiuminsulin infusions in the management of post-stroke hyperglycaemia: the UK Glucose Insulin in Stroke Trial (GIST-UK). Lancet Neurol. 2007;6(5):397-406.

75. Bruno A, Kent TA, Coull BM, et al. Treatment of hyperglycemia in ischemic stroke (THIS): a randomized pilot trial. Stroke. 2008; 39(2):384-389.

76. Johnston KC,HallCE, KisselaBM,BleckTP,ConawayMR. For the GRASP Investigators. Glucose Regulation in Acute Stroke Patients (GRASP) trial: a randomized pilot trial. Stroke. 2009;40(12):3804-3809.

77. Sheth KN, Kimberly WT, Elm JJ, et al. Pilot study of intravenous glyburide in patients with a large ischemic stroke. Stroke. 2014;45(1): 281-283.

78. Neumann-Haefelin T, Moseley ME, Albers GW. New magnetic resonance imaging methods for cerebrovascular disease: emerging clinical applications. Ann Neurol. 2000;47(5):559-570. 
79. Schaefer PW. Diffusion-weighted imaging as a problem-solving tool in the evaluation of patients with acute strokelike syndromes. Top Magn Reson Imaging. 2000;11(5):300-309.

80. Horstmann S, Kalb P, Koziol J, Gardner H, Wagner S. Profiles of matrix metalloproteinases, their inhibitors, and laminin in stroke patients: influence of different therapies. Stroke. 2003;34(9):2165-2170.

81. Montaner J, Alvarez-Sabín J, Molina C, et al. Matrix metalloproteinase expression after human cardioembolic stroke: temporal profile and relation to neurological impairment. Stroke. 2001;32(8):1759-1766.

82. Kimberly WT, Battey TW, Pham L, et al. Glyburide is associated with attenuated vasogenic edema in stroke patients. Neurocrit Care. 2014; 20(2):193-201.

83. Sheth KN, Kimberly WT, Elm JJ, et al. Exploratory analysis of glyburide as a novel therapy for preventing brain swelling. Neurocrit Care. 2014;21(1):43-51.
84. Sheth KN, Elm JJ, Molyneaux BJ, et al. Safety and efficacy of intravenous glyburide on brain swelling after large hemispheric infarction (GAMES-RP): a randomised, double-blind, placebo-controlled phase 2 trial. Lancet Neurol. 2016;15(11):1160-1169.

85. Zafardoost P, Ghasemi AA, Salehpour F, Piroti C, Ziaeii E. Evaluation of the Effect of Glibenclamide in Patients With Diffuse Axonal Injury Due to Moderate to Severe Head Trauma. Trauma Mon. 2016 Apr 24;21(5):e25113. doi: 10.5812/traumamon.25113. eCollection 2016 Nov. PubMed PMID: 28184360; PubMed Central PMCID: PMC5292034.

\section{Publish your work in this journal}

Drug Design, Development and Therapy is an international, peerreviewed open-access journal that spans the spectrum of drug design and development through to clinical applications. Clinical outcomes, patient safety, and programs for the development and effective, safe, and sustained use of medicines are the features of the journal, which has also been accepted for indexing on PubMed Central. The manuscript management system is completely online and includes a very quick and fair peer-review system, which is all easy to use. Visit http://www.dovepress.com/testimonials.php to read real quotes from published authors.

Submit your manuscript here: http://www.dovepress.com/drug-design-development-and-therapy-journal 